\title{
Coma Recovery Scale-Revised With and Without the Emotional Stimulation of Caregivers
}

\author{
Rita Formisano, Marianna Contrada, Marco Iosa, Giulia Ferri, Sara Schiattone, \\ Marta Aloisi
}

\begin{abstract}
The Coma Recovery Scale-Revised (CRS-R) is the gold standard of responsiveness assessment in patients with disorder of consciousness. The purpose of this study is to search for the efficacy of the caregivers' involvement in the evaluation of responsiveness in these patients. Responsiveness assessment was performed in 15 patients with CRS-R. The CRS-R was administered with and without the emotional stimulation of the primary caregiver at different times. Our preliminary findings seem to suggest that, including also the caregivers during CRS-R assessment, may obtain better responsiveness scoring than that obtained by professionals and might reduce the misdiagnosis rate.

RÉSUMÉ: Résultats à l'échelle d'évaluation d'éveil lors d'un coma avec ou sans la stimulation affective de personnes soignantes. L'échelle d'évaluation d'éveil lors d'un coma (Coma Recovery Scale-Revised) demeure la norme de référence en matière d'évaluation de la réactivité de patients aux prises avec des troubles de la conscience. L'objectif de cette étude est d'analyser l'impact de l'implication de personnes soignantes dans l'évaluation de la réactivité de ces patients. Une telle analyse a été effectuée chez quinze patients soumis à l'échelle d'évaluation d'éveil lors d'un coma, et ce, avec ou sans la stimulation affective d'une personne soignante et à différents moments. À cet égard, nos constatations préliminaires semblent indiquer que les scores de réactivité à cette échelle pourraient, en présence de personnes soignantes, dépasser ceux obtenus en compagnie de professionnels et ainsi réduire les taux de diagnostics erronés.
\end{abstract}

Keywords: Disorders of consciousness, Coma Recovery Scale-Revised, Emotional stimulation, Caregivers doi:10.1017/cjn.2019.227

Can J Neurol Sci. 2019; 46: 607-609

Misdiagnosis is one of the major concerns in Disorders of Consciousness (DoC). ${ }^{1}$ Confounding factors in the behavioral evaluation of overt responsiveness include comorbidities, ${ }^{2}$ extreme motor deficits and severe spasticity, ${ }^{3}$ diffuse pain, ${ }^{4}$ neuropsychological deficits, such as aphasia, ${ }^{5}$ psychomotor agitation, ${ }^{6}$ oppositive attitudes, and inertia, such as in akinetic mutism, ${ }^{7}$ as well as iatrogenic effects (anti-epileptics, sedative drugs, anti-spastic agents, etc.).

The Coma Recovery Scale-Revised $(\mathrm{CRS}-\mathrm{R})^{8}$ is the gold standard of responsiveness assessment in patients with DoC, as it has also been recently reported by the American guideline on this topic ${ }^{9}$; its advantages are the international validation of the scale, the diagnostic validity, the outcome prediction ability, and the standardization of the proposed stimuli. Conversely, its limitations might be considered the marginal role of the caregivers ${ }^{10}$ in the evaluation of patients' responsiveness, the poor emotional salience of the proposed stimuli, and the scarce motivational efficacy of standardized stimulations.

Sensory regulation and emotional stimulation have been previously proposed as a method to improve awareness in patients with altered states of consciousness. ${ }^{11,12}$

The principal aim of our study is to search for the possible efficacy of the caregivers' involvement in the evaluation of responsiveness in patients with DoC, in order to investigate a possible role of the caregiver in the improvement of the arousal, the interaction with the environment, and the functional communication recovery.

Fifteen patients (10 males and 5 females) with a mean age of $37.1 \pm 16.1$ years (range 15-60 years), diagnosed with DoC, according to the $\mathrm{CRS}-\mathrm{R}^{8}$ were consecutively enrolled in this study. Etiology was distributed as follows: 6 traumatic brain injury (TBI), 5 cerebral hemorrhage $(\mathrm{CH}), 3$ anoxia (A), and 1 cerebral ischemia (CI). All patients enrolled had normal auditory evoked potentials as an inclusion criterion. Responsiveness assessment was performed by two speech therapists (GF and SS) with long-term expertise in the evaluation of patients with DoC; both therapists have been involved in the Italian validation of the CRS-R ${ }^{13}$ and administered CRS-R at least five times during the first 2 weeks after admission, choosing the best scores obtained. The mean interval between coma onset and the first CRS-R assessment was $3.7 \pm 2.0$ months (range $1-8$ ). The two speech therapists administered CRS-R, without and with the emotional stimulation of the same primary caregiver, at study

From the IRCCS Santa Lucia Foundation, Rome, Italy (RF, MC, MI, GF, SS, MA) Received April 11, 2019. Final Revisions Submitted May 30, 2019. Date of ACCEPTANCE June 3, 2019.

Correspondence to: Rita Formisano, IRCCS Fondazione Santa Lucia, Via Ardeatina 306, 00179 Rome, Italy. Email: r.formisano@hsantalucia.it 


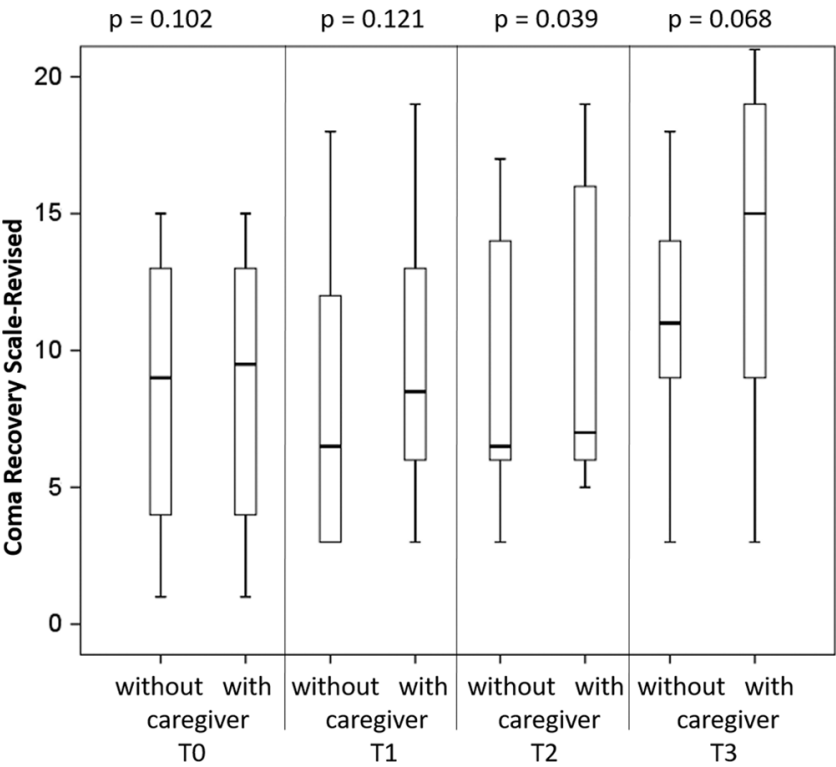

Figure 1: Box and whiskers plot of the total CRS-R scores assessed without (left bars) and with (right bars) the caregiver for the four assessment times (the above p-values were obtained comparing data obtained without and with caregiver for each assessment). The extremes of whiskers represent the minimum and maximum score, the limit of the box represents the first and third quartiles, and the bold line is the median score. Above p-values are related to the comparison.

entry (T0: number of patients $N=15$ ), after 1 month (T1: $4.6 \pm 2.0$ months, $\mathrm{N}=13$ ), after 2 months (T2: $5.0 \pm 1.91$ months, $N=12$ ), and at 1 -year follow-up (T3: $12.3 \pm 4.1$ months, $N=7$ ). The same items of the CRS-R were assessed by the speech therapist (professional alone) and by the speech therapist with the active participation of the "significant other" (caregiver) in different sessions.

Data were reported in terms of means and standard deviations. Comparisons between the CRS-R scores without and with the caregiver were performed using the Wilcoxon signed rank test, setting the alpha level of significance at $5 \%$.

Analyzing all 47 assessments independently by the assessment timing, the presence of caregiver implied 17 changes (36\%). The differences ranged from 0 up to 5 points of CRS-R being never negative, and those positive were mainly related to auditory and motor domains. The mean CRS-R was $8.3 \pm 5.0$ without the caregiver and $9.2 \pm 5.8$ with the caregiver, highlighting a statistically significant difference $(p=0.001)$. Analyzing each assessment timing, the CRS-R score was higher when the caregiver was present in 3 patients at $\mathrm{T} 0(p=0.102)$, in 5 at $\mathrm{T} 1(p=0.121)$, in 4 at $\mathrm{T} 2(p=0.039)$, and in 4 at T3 $(p=0.068)$, as shown in Figure 1.

Recent studies demonstrated the need to repeat CRS-R several times to patients with $\mathrm{DoC}$ in order to establish the responsiveness in the most appropriate and reliable way. ${ }^{14}$ Although our sample was progressively reduced by deaths or transfers, our preliminary findings seem to suggest that the inclusion of the caregiver during CRS-R assessment may give better responsiveness scoring than by professional alone, likely due to the emotional valence of the familiar voice, as previously reported..$^{15}$ It should be noted that only at T2 we found a significant difference between the CRS-R scores assessed with and without the caregiver, whereas no significant differences were noted at T0, T1, and T3. However, it is also worth noting that the presence of caregiver led to obtain higher CRS-R in 3, 5, and 4 patients also at T0, T1, and T3, respectively; and the CRS-R score assessed with the caregiver was never lower than that assessed without the caregiver. Thus, the involvement of caregivers in the evaluation of responsiveness in patients with DoC may enhance the efficacy of CRS-R and might reduce the misdiagnosis rate in patients with DoC. ${ }^{1}$

\section{FUNDING}

This work has received funding from the European Union's Horizon 2020 research and innovation programme under the Marie Skłodowska-Curie grant agreement no. 778234 .

\section{Disclosures}

The authors have no conflicts of interest to declare.

\section{STATEMENT OF AUTHORSHIP}

RF has supervised the whole Project, since the beginning, and has written the paper with MC and MA; MC, GF, SS, and MA have participated in the data collection; and MI has performed the statistical analysis.

\section{REFERENCES}

1. Schnakers C, Vanhaudenhuyse A, Giacino J, et al. Diagnostic accuracy of the vegetative and minimally conscious state: clinical consensus versus standardized neurobehavioral assessment. BMC Neurol. 2009;9(1):35.

2. Estraneo A, Loreto V, Masotta O, et al. Do medical complications impact long-term outcomes in prolonged disorders of consciousness? Arch Phys Med Rehabil. 2018;99(12):2523-31.

3. Thibaut A, Chatelle C, Wannez S, et al. Spasticity in disorders of consciousness: a behavioral study. Eur J Phys Rehabil Med. 2015;51(4):389-97.

4. Formisano R, Contrada M, Aloisi M, et al. Nociception Coma Scale with personalized painful stimulation versus standard stimulus in non-communicative patients with disorders of consciousness. Neuropsy Rehab. 2019;15:1-12.

5. Formisano R, Toppi J, Risetti M, et al. Language-related brain potentials in patients with disorders of consciousness: a follow-up study to detect "covert" language disorders. Neurorehabil Neural Repair. 2019;33(7):513-522.

6. Formisano R, Bivona U, Penta F, et al. Early clinical predictive factors during coma recovery. Acta Neurochir. 2005;93:201-5.

7. Formisano R, D'Ippolito M, Risetti M. Vegetative state, minimally conscious state, akinetic mutism and Parkinsonism as a continuum of recovery from disorders of consciousness: an exploratory and preliminary study. Funct Neurol. 2011;26(1):15.

8. Giacino JT, Kalmar K, Whyte J. The JFK coma recovery scalerevised: measurement characteristics and diagnostic utility. Arch Phys Med Rehabil. 2004;85(12):2020-29.

9. Giacino JT, Katz DI, Schiff ND, et al. Practice guideline update recommendations summary: disorders of consciousness: report of the Guideline Development, Dissemination, and Implementation Subcommittee of the American Academy of Neurology; the American Congress of Rehabilitation Medicine; and the National Institute on Disability, Independent Living, and Rehabilitation Research. Arch Phys Med Rehabil. 2018;99(9):1699-1709.

10. Sattin D, Giovannetti AM, Ciaraffa F, et al. Assessment of patients with disorder of consciousness: do different coma recovery scale scoring correlate with different settings? J Neurol. 2014; 261(12):2378-86.

11. Moattari M, Shirazi FA, Sharifi N, et al. Effects of a sensory stimulation by nurses and families on level of cognitive function, and basic cognitive sensory recovery of comatose patients with severe traumatic brain injury: a randomized control trial. Trauma Mon. 2016;21(4):23531. 
12. Salmani F, Mohammadi E, Rezvani M, et al. The effects of familycentered affective stimulation on brain-injured comatose patients' level of consciousness: a randomized controlled trial. Int J Nurs Stud. 2017;74:44-52.

13. Estraneo A, Moretta P, De Tanti A, et al. An Italian multicentre validation study of the coma recovery scale-revised. Eur J Phys Rehabil Med. 2015;51(5):627-34.
14. Wannez S, Heine L, Thonnard M, et al. The repetition of behavioral assessments in diagnosis of disorders of consciousness. Ann Neurol. 2017:81(6):883-9.

15. de Pasquale F, Caravasso CF, Péran P, et al. Functional magnetic resonance imaging in disorders of consciousness: preliminary results of an innovative analysis of brain connectivity. Funct Neurol. 2015;30(3):193. 